\title{
A CROSS SECTIONAL STUDY AMONG MEDICAL COLLEGE STUDENTS TO FIND OUT THE LEVEL OF STRESS, LONELINESS \& DEPRESSION.
}

KEY WORDS: medical Students, Stress, Depression.

\section{Thakur Madhur}

\section{Chouhan Vijay}

\section{Dangi Thansingh}

\section{Thakur Vipin*}

MBBS, Junior Resident, Dept of Obstetrics and gynaecology, Govt. Medical College, Ratlam, (MP) India.

MBBS, MS Assistant Professor, Dept. of Anatomy, Govt. Medical College, Ratlam, (MP) India.

MSC, M.LIB, Librarian Dept. of Central Library Govt. Medical College, Ratlam, (MP) India.

MBBS, MD, Senior Resident Dept. of pediatrics, Gandhi Medical College, Bhopal, (MP) India. *Corresponding Author

Aim of the Study: To assess the level of stress, loneliness and depression among medical college students.

Background: A recent shift across industrialized societies is characterized by an increase in the number of people pursuing post-secondary education. This shift has created a new stage in the life span that describes the lives of young people and is called, emerging adulthood. Individuals in emerging adulthood are in their late teens and early 20 s. Emerging adulthood is defined as the stage of life that includes young individuals who range from 18 to 25 years, and in characterized by frequent change, independence and exploration.

Method: The Following is cross sectional study on 150 medical college students in Indore at MGM Medical College to find out the level of stress, loneliness and depression in students. The data was collected through a predesigned semistructured questionnaire which consisted of 13 questions. The study was conducted for the duration of three months through simple random sampling method.

Result: There are $52.35 \%$ male and $47.65 \%$ females. In terms of locality, we studied there $43.62 \%$ are hostellers $30.20 \%$ locals, and $26.17 \%$ paying guests. By Applying Person co-relation test, we find that there is significant negative corelation of age with stress, loneliness and depression. On other way by applying independent T-Test we find that there is significant relation of gender with level of stress, level of loneliness and level of depression.

Conclusion: By Applying Person Co-relation test we find that there is significant negative co-relation of age with stress Loneliness and depression Hence we find that with increase in age is associated with decrease in stress loneliness and depression. Applying independent T-Test find that there is significant relation of gender with level of stress level of loneliness and level of depression we conclude that female medical students have more stress, loneliness and depression in female as compared to male.

\section{INTRODUCTION:}

Emerging adulthood is defined as the stage of life that includes young individuals who range from 18 to 25 years, and is characterized by frequent change, independence, and exploration ${ }^{1}$.During emerging adulthood, work is considered preparation for later adult work. This is now the time when the ground work is laid for jobs and careers pursued during adulthood ${ }^{2}$. The transition to college allows the emerging adult to create a separate residence from the family, establish a lifestyle, and explore future career paths and possibilities for work ${ }^{3}$. For the most part, loneliness research has tended to center around on individual factors that is either on personality factors or lack of social contacts ${ }^{4}$. However, the experience of loneliness is likewise unpleasant and distressing. Loneliness may also lead to people to submerge themselves into dependency relation, following direction, imitation, being like others, and striving for power and status ${ }^{5}$. Depression is a common mental disorder, characterized by sadness, loss of interest or pleasure, feelings of guilt or low self-worth, disturbed sleep or appetite, feelings of tiredness, low energy and poor concentration. Depression has a significant impact on an individual's ability to perform life activities $^{6}$. Although low self-worth has been conceptualized as both a cause and consequence of depression, it is not synonymous with depression, which includes a variety of other features ${ }^{7}$.

Approval of Intuitional Ethical Committee: The research protocol was approved by institutional ethics.

\section{METHODS:}

This is a cross sectional study on 150 medical students in Indore at MGM Medical College to find out the existing relationship between their age and gender with the level of stress, loneliness and depression in students. The data was collected through a predesigned semi-structured questionnaire which consisted of 13 questions. Respondents gave their answer by grading between 1 to 5 which illustrate never, almost never, sometimes, often, and always. The study was conducted for the duration of three months through simple random sampling method.

Inclusion Criteria: Undergraduate medical students who gave consent were included in this study.

Exclusion Criteria: Postgraduates, interns and paramedic students were not included in the study.

\section{OBSERVATION AND RESULT:}

Statistical analysis was performed by using appropriate software.We use statistical tools Person correlation coefficient comparing the level of stress, loneliness and depression with respect to sex, and age in medical students. In our study there are students between the ages of 18 to 24 year. Also, there are $52.35 \%$ male and $47.65 \%$ females. In terms of locality, we studied there $43.62 \%$ are hostellers, $30.20 \%$ locals, and $26.17 \%$ paying guests.

Graph-01 showing level of stress with age Average of Stress

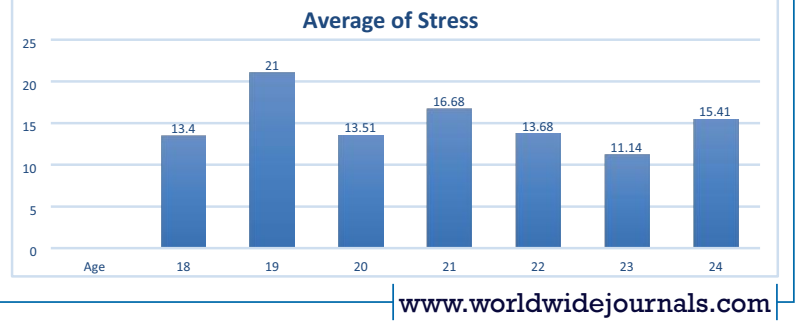


Interpretation:-By Applying Pearson co-relation test we find that there is significant negative co-relation between age and stress.

Graph-02 showing level of loneliness age.

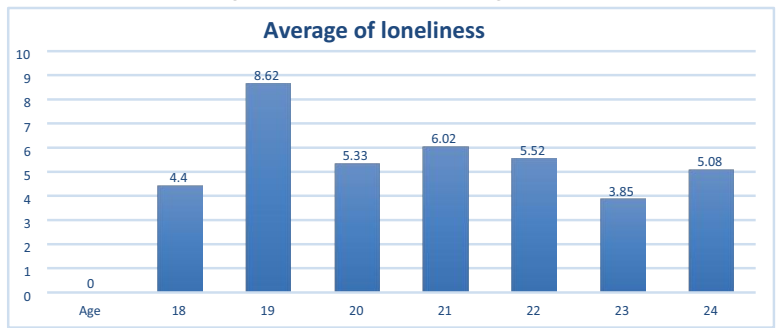

Interpretations: - By Applying Pearson co-relation coefficient test we find that there is significant negative co-relation between age and loneliness. So, with increase in age there is decrease in loneliness.

\section{Graph-03 showing level of depression with age.}

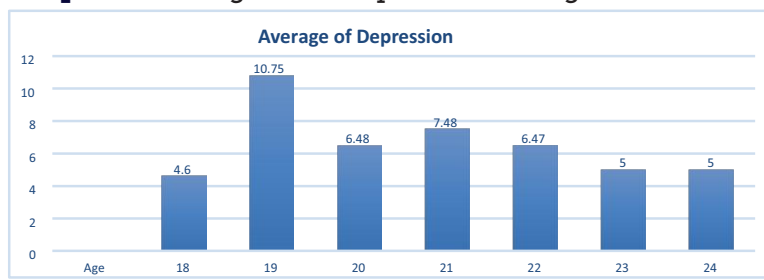

Interpretations: - By Applying Pearson co-relation coefficient test we find that there is significant negative co-relation between age and depression.

\section{DISCUSSION:}

By Applying Person Co-relation test, we find that there is significant negative correlation of age with stress, loneliness and depression. Hence, we find that with increase in age is associated with decrease in stress, loneliness and depression. First, with increase in age there is decrease in stress. This finding is similar to the literature that predominantly points to the negative association between perceived stress and age (e.g.,Aldwin 1991: Brummer et al 2014), such that individuals who are older experience lower levels of perceived stress ${ }^{8}$ As student get into college, they come across new environment, new people which lead to anxiety and stress in them as they get adjusted stress level decreases.

Secondly, there is decrease in loneliness with increase in age. Because student get into college, they come across new environment, new people which lead to loneliness but as they get comfortable with people around them and interact with them so loneliness decreases. Finally with increase in age there is decrease in depression. This trend is similar to loneliness data found in our study. This is supported by older researches. AbdurRehmanet al revealed Positive correlation between loneliness and depression is students. It reveals moderately significant relation between the loneliness and depression level of students. It mentioned that students might have the symptoms of the both loneliness and depression together ${ }^{9}$.

Applying independent T-test we find that there is significant relation of gender with level of stress, level of loneliness and level and depression in female as compared to male. To begin with, there is more level of stress in female as compared to male. As in our Indian Society there is more restricts and bias applied to girls as compared to boys so that boys seemed to be more carefree and less stressed. Secondly, there is more level of loneliness in female as compared to male. This is in contrast with the older researches, UgurOzdemir and Tarik tuncay found out that there was no statistically significant correlation between the gender and age of the students and the level of loneliness ${ }^{10}$. Finally, there is more level of |www.worldwidejournals.com | depression in females than males. This is in contrast with Abdur Rahman et al who revealed that gender has no significant effect on student's depression ${ }^{9}$. The causes of the findings can be explained by, gender roles, inter-personal relationship, multidimensional phenomenon of perception of loneliness.

\section{SUMIMARY AND CONCLUSION:}

Hence we find that with increaser in age associate with decrease in stress, loneliness and depression, applying indecent T-Test we find that there is significant relation of gender with level of stress, level of loneliness and level of depression we conclude that female medical students have more stress, loneliness and depression in female as compared to male.

Conflict of interest: The authors declared that there is no conflict of interest.

\section{REFERENCES:}

1. College Student and their relationships with parents" (mary Elizabeth curtner-smith. Blake berryhill. Wright:2016) by the university of Alabama.

2. How emerging adults are influenced by their parents" current parenting behaviors (Nelson rt at.2011).

3. Dimensionality of helicopter parenting and relation to emotion decision -making . and academic functioning in emerging adults Aaron M. Lauren, Kathryn J.Mancini, Elizabeth J.Kiel, Brooke R. Spangler, Julie L. Semlak, Lauren M.Fussnerhttps://journals.sagepub.com/doi/10.1177/1073191116665907

4. DiTommaso E, Brannen-McNulty C, Ross L, Burgess M: Attachment styles, social skills and loneliness in young adults. Personality and Individual Differences 2003,35:303-312.

5. Peplum LA: Loneliness: A Sourcebook of Current Theory, Research and Therapy.John Wiley \& Sons Australia, Limited; 1982.

6. GREENBERG, P., STIGLIN, L., FINKELSTEIN, S. AND BERNDT, E.R.1990. The economic burden of depression. Journal of clinical Psychiatry. 54 (11): 405418 .

7. Harter,S.(1999). The construction of self:A development perspective. New York: Guilford Press.

8. The Influence of Age on Emotion Regulation Strategies and Psychological Distress aura BummerLuciaStopaRomola S BucksArticleinBehavioral and Distress aura BummerLuciaStopaRomola S BucksArticleinBehaviora
Cognitive Psychotherapy · July 2013DOI: 10.1017/S1352465813000453

9. Loneliness and depression of university students Abdur Rahman, Arunavo Bairagi, Biplob Kumar Dey \&Lailun Nahar The Chittagong University J. of Biological Science, vol-7 (1\&2),2012, 175-18

10. Correlates of loneliness among university students UgurÖzdemir and Tarik Tuncay*Child and Adolescent Psychiatry and Mental Health 2008, 2:29 doi:10.1186/1753-2000-2-29. 